http://dx.doi.org/10.23925/2176-2767.2019v64p354-361

Recebido em: 23/09/2018

Aprovado em: 15/01/2019

\title{
RESENHA
}

\section{EXISTEM LIMITES PARA A BIOGRAFIA?}

IGOR LEMOS MOREIRA*

AVELAR, Alexandre de Sá; SCHMIDT, Benito Bisso (Orgs.). O que pode a biografia. São Paulo: Letra e Voz, 2018.

Aguardada desde a publicação de Grafia da vida: reflexões e experiências com a escrita biográfica (2013), a nova coletânea de textos organizada por Alexandre de Sá Avelar e Benito Bisso Schmidt a respeito do gênero biográfico foi lançada em 2018. Publicado pela editora Letra e Voz, o livro intitulado $O$ que pode a biografia segue a mesma proposta da primeira obra: a reunião de textos téorico-metodológicos e relatos de experiências sobre a produção de biografias. Esse processo é perceptível, inclusive, nas diferenças de estruturação de ambas as obras. Enquanto a coletânea de 2013 foi organizada em três eixos reunindo onze autores (além da apresentação feita por Marieta Ferreira), a publicação de 2018 é dividida apenas em dois, focando, através de doze capítulos, nos elementos teóricos e nas práticas.

Iniciando com uma concisa apresentação, que faz referência a própria continuidade do trabalho iniciado em 2013, os organizadores afirmam que o livro nasce em um contexto de sedução pelo gênero biográfico no país, aumentando o número de interessados e convocando novas reflexões no campo das humanidades e das letras. Em seguida, são 
apresentados cinco textos que debatem a biografia a partir de seus "horizontes teórico-metodológicos". Em "Contar vidas em uma época presentista: A polêmica sobre a autorização prévia", Benito Schmidt retoma o tema da Ação Direta de Inconstitucionalidade (ADI) movida em 2015 pela ANEL, onde se previa a necessidade de anuência prévia concedida pelo biografado ou seus familiares ao escritor/pesquisador. Partindo da ADI e de casos brasileiros, como a polêmica envolvendo o historiador Paulo Cesar de Araújo ${ }^{1}$, o autor reflete sobre os regimes de historicidade, com ênfase no presentismo (HARTOG, 2013), e nas disputas de memórias que cercam o tema. Em seu texto, Schmidt pensa a constituição do campo biográfico na historiografia, entendendo as múltiplas temporalidades que transitam dentro do processo que chamou de "a biografia em julgamento".

Em Os usos da biografia pela micro-história italiana: interdependência, biografias coletivas e network analysis, Deivy Ferreira Carneiro aborda as relações entre micro-história e biografia sob a chave de análise das experiências, das relações e do contexto social. Partindo da micro-história, o autor procura entender os sujeitos biografados como relacionais, pertencentes a determinados grupos e redes o que aproximaria a biografia da microhistória. Tal processo também rompe com a própria certeza da vida dos sujeitos biografados e com a ideia da linearidade das biografias produzidas predominantemente até o século XX. Segundo o autor, "a maior contribuição trazida pelo debate microanalítico acerca da biografia, a meu ver, foi trazer à tona um indivíduo cheio de incertezas que, na verdade, não tem uma percepção clara de si mesmo. (CARNEIRO, 2018. p. 56).

Maria da Glória de Oliveira, em Para além de uma ilusão: indivíduo, tempo e narrativa biográfica, dá seguimento à temática do sujeito, pensando a 
construção das trajetórias através dos processos de mediação narrativa, partindo de Pierre Nora. Historicizando a própria biografia, a historiadora tece sua reflexão acerca do papel da construção narrativa, especialmente da intriga, como maneira de "confrontar o indivíduo com a experiência do tempo" (OLIVEIRA, 2018. p. 61). Retomando também a noção de ilusão biográfica se destaca a compreensão que uma trajetória, e a experiência dos biografados, ocorre através não apenas de sua inserção contextual, mas igualmente da configuração do ato narrativo pelo qual essas experiências são materializadas.

A temática da narrativa é continuada por Mary Del Priore, autora de Biografia, biografados: uma janela para a história. Através também de uma historicização do gênero, Del Priore problematiza como os próprios historiadores opinaram e se relacionaram com as biografias. Em suas análises a autora reflete sobre as relações entre História e Literatura nesse processo, além de provocar o leitor a refletir sobre a própria disciplina e o lugar social e narrativo dos historiadores.

O último texto da seção, "Histórias de vida: um lugar de resistência para a reportagem", é assinado por Rose Silveira. Destacando a distinção entre reportagem e notícia, a autora discute as possibilidades de pensar o livro-reportagem como uma forma de escrita biográfica. Aproximando História e Comunicação, o capítulo pontua elementos centrais da relação, abrindo espaço para reflexão sobre outras formas de produção de biografias no presente por não-historiadores. Como a autora destaca, esse processo ocorre através da noção de operação historiográfica a partir de Michel de Certeau. Por fim, visando exemplificar seus argumentos, Silveira analisa as 
biografias: A vida imortal de Henrietta Lacks (Rebecca Skloot) e Marighella: o guerrilheiro que incendiou o mundo (2012).

A segunda parte do livro, que reúne sete textos que apresentam como os enfoques teórico-metodológicos discutidos anteriormente perpassam as "experiências de pesquisa e leitura" de biografias. O texto que abre a sessão, assinado por Alexandre de Sá Avelar, discute a experiência de escrita de uma vida a partir da ideia de trajetória, o que foge do perfil totalizante da biografia. Procurando repensar o processo de elaboração de sua tese de doutorado defendida em 2006, o autor, em $O$ reencontro com o general e o meu labirinto: sobre a releitura de uma tese, reflete sobre os meandros da pesquisa, suas motivações e principalmente os processos de delimitação do enfoque teórico. Avelar destaca que apesar de focalizar na trajetória de um individuo, isso não o excluiu "das preocupações propriamente biográficas" (AVELAR, 2018. p. 131). Sua noção de trajetória não se opõe à de biografia. Trata-se de uma forma da compreensão de um personagem através de uma proposta especifica ou um fio condutor em especial, que em seu caso foi a leitura da produção de Macedo Soares como modo de entendimento da estabilização dos processos de consolidação do capitalismo industrial brasileiro.

Dando seguimento ao relato de Avelar, Francisco Martinho aborda sua relação com o português Marcello Caetano, pensando os percursos que o levaram a produzir uma biografia política e intelectual sobre essa figura. Marcello Caetano: sobre a travessia de uma pesquisa é um relato de pesquisa primoroso no sentido que demonstra não apenas o processo de elaboração da biografia, mas compartilha as angústias e os desafios desse gênero de produção, especialmente com sujeitos que viveram em outros países que 
não o de origem do biografo. Abordando os limites e dificuldades da pesquisa, inclusive de acesso a documentações no exterior, Martinho lembra ao leitor a importância de se reconhecer a impossibilidade de apreensão total da vida de um sujeito, principalmente de maneira linear.

Em seguida, o brasilianista James Green nos presenteia com um relato sobre os bastidores de sua obra recentemente publicada pela Editora Civilização Brasileira. Green faz uma analogia direta aos próprios dilemas que perpassam a segunda seção da coletânea ao intitular seu texto como "Herbert Daniel: revolucionário e gay, ou é possível captar a essência de uma vida tão extraordinária". Pensando a relação biografo e biografado, o historiador compartilha dilemas muito semelhantes aos dos dois textos anteriores, mas aponta outro elemento: a proximidade temporal e pessoal com o tema, marcada especialmente pelo potencial uso da história oral. Narrando, por exemplo, suas tentativas de diálogo com parentes de Daniel, o autor destaca como um personagem é construído, através dos rastros e das memórias, pelo próprio pesquisador apenas no decorrer da própria pesquisa.

A questão dos rastros é retomada em seguida por Jorge Ferreira em Escrevendo João Goulart. Autor de uma das obras de não ficção mais vendidas de 2011 (FERREIRA, 2016), o pesquisador destaca seus processos de pesquisa, assim como os acasos e momentos inesperados de acesso da documentação. Apesar dos pontos de contato com os relatos anteriores, Ferreira atenta algumas questões próprias de pesquisadores da área de história política e econômica. Nesse sentido, uma das principais contribuições de seu texto é reforçar que o sujeito é, não apenas relacional 
com seu contexto, mas também "conformado por estruturas econômicas ou pelas ideias de classe social” (FERREIRA, 2018. p. 182).

A temática da autobiografia é discutida nos dois textos seguintes da coletânea. Laura de Mello e Souza, em "Vitório Alfieri, a vida e a história", mergulha em suas memórias com Vitório Alfieri e sua obra autobiográfica Vita produzindo um ensaio sobre a trajetória e o desenvolvimento intelectual de um dos autores que mais a intrigaram. Nesse sentido, mais do que pensar o procedimento de uma biografia escrita por ela, Mello e Souza reflete também sobre os processos de construção autobiográfica do escritor do século XIX.

Em seguida, "autobiografia, gênero e escrita de si: nos bastidores da pesquisa”, de Margareth Rago, constrói uma reflexão autobiográfica de seu envolvimento com o tema das autobiografias apresentando ao leitor suas inspirações, motivações, estratégias e referências. Seu capítulo propõem ao leitor compreender as tecituras da composição dos sujeitos, que nunca se veem totalmente excluídos de processos e estruturas maiores como o gênero, ou ainda a dimensão coletiva existente na própria produção de si.

O último texto da seção é, certamente, um dos mais intrigantes. Temístocles Cezar, em "Bartleby e Nulisseu: a arte de contar histórias de vida sem biografia", brinca em um eterno jogo entre realidade e ficção ao narrar a história de Nilusseu, uma jovem estudante de história encantada com Bartleby, personagem do conto de Herman Melville, publicado em 1853. Em uma trama instigante e reflexiva, permeada por referências a teóricos como Marx, Hegel, Foucault, assim como estudiosos das teorias da biografia como Sabina Loriga, Cezar provoca o leitor a refletir sobre as possibilidades de escrever uma história de vida sem fazer biografia. 
Colocando sob sua mira a própria ideia dos indivíduos serem ou não únicos, o autor nos instiga a refletir sobre quem determina essa individualidade e protagonismo dos sujeitos. Mais que isso sua trama possibilita pensar a ideia de ilusão biográfica, ao intrigar o leitor com a jovem Nilusseu que se confunde ao seu próprio mundo de leituras.

A pergunta inevitável que marca esse capítulo - e penso não ser a toa os organizadores o terem colocado como o último texto do volume -, seria: é possível contar histórias de vida sem biografia, se afinal existem histórias no plural? Penso que a estruturação da obra caminha para esse ponto central. A coletânea, O que pode a biografia não fornece um manual prático sobre como trabalhar ou pesquisar o gênero. Ao mesmo tempo, sua intenção também não é o que o título poderia sugerir: um manifesto acerca das regras e diretrizes do campo. A obra organizada por Avelar e Schmidt convoca a uma reflexão sobre um campo aberto e de fronteiras móveis.

Apesar das conexões, cada texto elencado apresenta pontos de vista únicos sobre o fazer biográfico. "Pode a micro-história dialogar com a biografia? São campos iguais?" "Somente historiadores produzem biografias?" "Não seria toda forma de escrita uma auto-biografia?" “Biografia e trajetória são campos distintos?” são apenas algumas das reflexões provocadas, não tendo por objetivo fornecer respostas definitivas. Passando da teoria a prática, os textos demonstram a impossibilidade do próprio pesquisador ver esses dois campos como dimensões dissociadas. Em momentos de crise da história e de consolidação e crescimento da história pública $O$ que pode a biografia é um sopro renovador ao campo.

\section{Referências}


AVELAR, Alexandre de Sá; SCHMIDT, Benito Bisso (Orgs.). Grafia da vida: reflexões e experiências com a escrita biográfica. São Paulo (SP): Letra e Voz, 2012.

FERREIRA, Jorge. De volta ao público: João Goulart, uma biografia. MAUAD, Ana Maria; ALMEIDA, Janiele Rabêlo de; SANTIAGO, Ricardo (Org). História Pública no Brasil: Sentidos e Intinerários. São Paulo: Letra e Voz, 2016. p. 121-131.

HARTOG, François. Regimes de Historicidade: Presentismo e Experiências do Tempo. Belo Horizonte, Mg: Autêntica, 2014.

OLIVEIRA, Márcia Ramos de Oliveira. Reflexões sobre o gênero biográfico: literatura, ilusão e disputas de memória. In: GONÇALVES, Janice (Org.) História do Tempo Presente: Oralidade, memória, mídia. Itajaí: Casa Aberta, 2016. p. 101-116.

\section{Notas}

\footnotetext{
* Mestrando no Programa de Pós-Graduação em História da Universidade do Estado de Santa Catarina. Bolsista CAPES-DS e Integrante do Laboratório de Imagem e Som. Email: igorlemoreira@gmail.com. Número do ORCID: https://orcid.org/0000-00016353-7540. O presente trabalho foi realizado com apoio da Coordenação de Aperfeiçoamento de Pessoal de Nível Superior - Brasil (CAPES) - Código de Financiamento 001.

${ }^{1}$ Em um texto recente, a pesquisadora Márcia Ramos de Oliveira (2016), também discutiu os embates em torno do gênero biográfico ocorridos na sociedade brasileira a partir de 2015. Apesar de ambos focalizarem temáticas semelhantes, a autora destaca principalmente os diferentes embates de memória, ligados a narrativa, focando especificamente no caso de Paulo Cesar de Araújo.
} 